\title{
Respiratory failure in a cancer patient: pulmonary thrombotic microangiopathy
}

\author{
Authors: Robert M Venn, ${ }^{A}$ Emma Parkes, ${ }^{B}$ Anurag Joshi, ${ }^{C}$ Edward JD Caple ${ }^{B}$ and Helen E Davies ${ }^{D}$
}

The hypoxic patient with a normal chest X-ray can be a diagnostic challenge. This case illustrates the rational diagnostic process and describes a relatively rare but important complication of cancer metastasis. Thrombotic microangiopathy, like lymphangitis carcinomatosa, may cause respiratory failure and is a poor prognostic finding. However, unlike lymphangitis carcinomatosa, it may not have specific findings on cross-sectional imaging.

KEYWORDS: Respiratory failure, hypoxaemia, thrombotic, microangiopathy

DOI: 10.7861/clinmed.2020-0102

\section{Case presentation}

A 34-year-old woman visiting our area presented to the emergency department with breathlessness. She gave a 10 -week history of insidious exertional dyspnoea and reported 2 days of non-specific right-sided chest discomfort. There was no cough, fever or weight loss. Her past history included breast cancer 6 years previously, managed with wide local excision, adjuvant radiotherapy and chemotherapy (epirubicin and docetaxel) followed by tamoxifen. She had never smoked. Two weeks earlier, she had been admitted to her local hospital for the same complaint and she was discharged with reassurance after investigation (computed tomography pulmonary angiography (CTPA), echocardiography and lung function tests).

On examination, her oxygen saturation was $94 \%$ on air, respiratory rate 14 breaths/min, heart rate 82 beats/min and blood pressure $118 / 74 \mathrm{mmHg}$. The remainder of the physical examination was normal and her blood count, electrolytes, $\mathrm{C}$-reactive protein (CRP) and troponin were normal; D-dimer was positive. The chest X-ray was normal.

The admitting doctor considered the most likely diagnosis to be pulmonary embolism and prescribed therapeutic

Authors: ${ }^{\text {A }}$ medical registrar, University Hospital Llandough, Cardiff, UK; ${ }^{B}$ senior house officer, University Hospital Llandough, Cardiff, UK; Chistopathologist, University Hospital Llandough, Cardiff, UK; ${ }^{D}$ consultant physician, University Hospital Llandough, Cardiff, UK low-molecular-weight heparin. The consultant physician, noting the relatively low oxygen saturation, requested arterial blood gas $(A B G)$ sampling and oxygen saturation following ambulation.

$\mathrm{ABG}$ analysis breathing ambient air revealed $\mathrm{pH} 7.48, \mathrm{pO}_{2} 8.4$ $\mathrm{kPa}, \mathrm{pCO}_{2} 3.7 \mathrm{kPa}$. After walking $30 \mathrm{~m}$, oxygen saturation fell to $82 \%$; it improved to $97 \%$ on breathing $2 \mathrm{~L} / \mathrm{min}$ supplemental oxygen.

\section{Differential diagnosis of hypoxaemia}

Pulse oximetry measures haemoglobin oxygen saturation. Exertional desaturation may be seen in patients with normal or near-normal resting levels. ${ }^{1}$ Hypoxaemia results from a limited number of mechanisms (Table 1); when the cause is not obvious, it is helpful to consider these systematically. ${ }^{2}$

$A B G$ analysis yields additional information. The alveolar-arterial (A-a) oxygen gradient is the difference between the partial pressures of oxygen in the alveoli $(A)$ and the arteries (a):

$$
\text { A-a gradient }=\mathrm{p}_{\mathrm{A}} \mathrm{O}_{2}-\mathrm{p}_{\mathrm{a}} \mathrm{O}_{2}
$$

The normal value is $\leq 2 \mathrm{kPa}$ in young to middle-aged people and $\leq 3 \mathrm{kPa}$ in older people. A gradient higher than this suggests underlying abnormal gas exchange, rather than hypoventilation. The (arterial) $\mathrm{p}_{a} \mathrm{O}_{2}$ is measured directly; however, the (alveolar) $\mathrm{p}_{\mathrm{A}} \mathrm{O}_{2}$ is estimated using the alveolar gas equation (Fig 1 ).

\section{Table 1. Mechanisms of hypoxaemia and clinical \\ examples}

$\begin{array}{ll}\begin{array}{l}\text { Category } \\ \text { Reduced atmospheric } \\ \text { oxygen }\left(\mathrm{p}_{\text {atmos }} \mathrm{O}_{2}\right)\end{array} & \begin{array}{l}\text { Examples } \\ \text { Altitude }\end{array} \\ \text { Alveolar hypoventilation } & \begin{array}{l}\text { Airways disease, neuromuscular } \\ \text { disease etc }\end{array} \\ \begin{array}{l}\text { Pulmonary ventilation/ } \\ \text { perfusion mismatch }\end{array} & \begin{array}{l}\text { Pneumonia, pulmonary embolism } \\ \text { etc }\end{array} \\ \begin{array}{l}\text { Diffusion limitation } \\ \text { Shunt }\end{array} & \begin{array}{l}\text { Interstitial oedema or inflammation } \\ \text { Atrial septal defect, tetralogy of }\end{array} \\ \text { Reduced mixed venous } \\ \text { oxygen }\left(\mathrm{p}_{\bar{v}} \mathrm{O}_{2}\right)\end{array} \quad \begin{aligned} & \text { Fallot etc } \\ & \text { Cardiogenic or hypovolaemic shock }\end{aligned}$




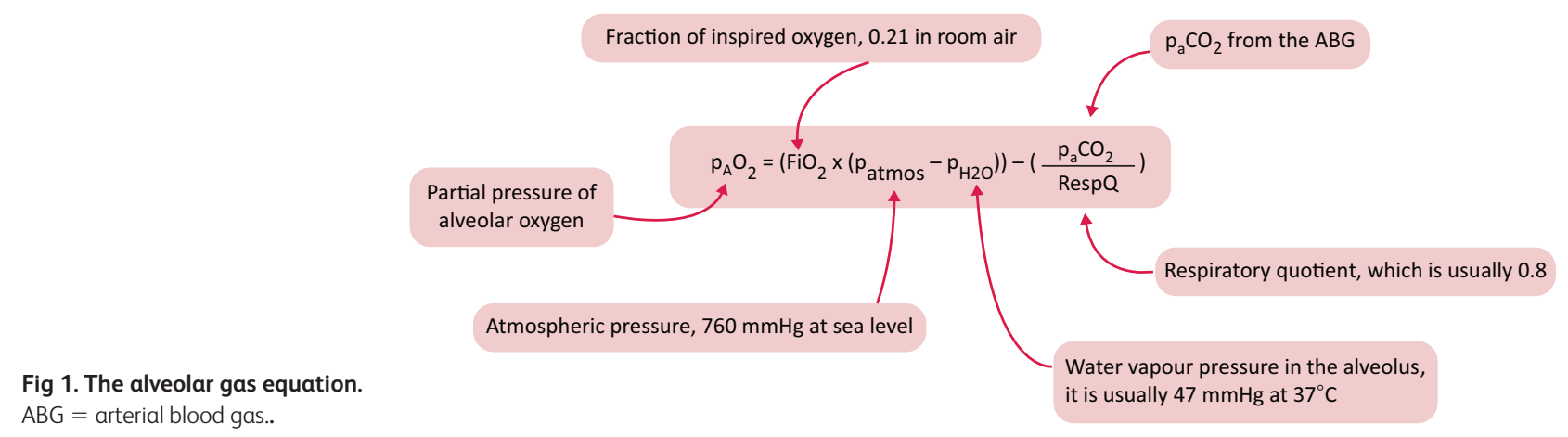

Our patient's A-a gradient was calculated:

$$
\begin{aligned}
& \text { A-a gradient }=\mathrm{p}_{\mathrm{A}} \mathrm{O}_{2}-\mathrm{p}_{\mathrm{a}} \mathrm{O}_{2} \\
& =(0.21(101.3-6.2)-(3.75 / 0.8))-8.4 \\
& \approx 6.9 \mathrm{kPa}
\end{aligned}
$$

Elevation of her A-a gradient narrows the possible pathological mechanisms to:

> ventilation/perfusion ( $\left.V^{\prime} / Q^{\prime}\right)$ mismatch

$>$ right-to-left shunting

$>$ diffusion limitation.

\section{Further investigations}

CTPA showed no pulmonary emboli or evidence of a pulmonary arteriovenous malformation; anticoagulation was stopped. A right-to-left shunt was considered, but excluded following bubble contrast echocardiography. In this technique, agitated saline is injected intravenously: bubbles should appear in the right atrium and ventricle but, if seen on the left side of the heart, imply the presence of a septal defect. However, despite 'no obvious shunt', pulmonary hypertension with raised right ventricular systolic pressure and impaired right ventricular function was apparent.

Detailed pulmonary function at rest revealed a restrictive ventilatory defect with reduced gas transfer: lung transfer factor for carbon monoxide $\left(t_{L} C O\right)$, alveolar volume $\left(v_{A}\right)$ and transfer coefficient $\left(\mathrm{kCO}\right.$ ) were reduced. $\mathrm{t}_{\mathrm{L}} \mathrm{CO}$ reflects the transfer of $\mathrm{CO}$ gas across the alveolar membrane and its subsequent removal in the pulmonary circulation. A reduction in $\mathrm{kCO}$, which is independent of $v_{A}$, implies that the reduced transfer factor cannot be solely due to the reduced alveolar volume - hence there must be diffusion limitation (eg interstitial disease) or perfusion limitation (vascular disease).

Armed with this information, a high-resolution expiratory phase thoracic CT was arranged. No air trapping was seen, but the reporting radiologist commented on 'very mild centrilobular nodularity'. In addition, an isotope ventilation/perfusion ( $V^{\prime} / Q^{\prime}$ ) scan was done, which may be more sensitive for detection of thromboembolic disease., 3,4 This showed 'multiple segmental and subsegmental perfusion defects in both lungs ... highly suspicious for multiple pulmonary emboli'. Anticoagulation was restarted.

\section{Clinical progress}

Despite treatment for pulmonary thromboembolism, our patient's clinical condition deteriorated with worsening dyspnoea, more rapid and substantial exertional desaturation (to low 70 s\%) and an increasing, continuous oxygen requirement. The failure to respond to routine anticoagulation raised concern about the possibility of tumour thromboemboli (thrombotic microangiopathy). After multidisciplinary discussion, a surgical lung biopsy was considered; however, on the day prior to planned surgery, the patient's hypoxia worsened. Clinical examination was unchanged apart from tachypnoea ( 26 breaths/min) and tachycardia (130 beats/min), and a chest X-ray was unremarkable. $\mathrm{ABG}$ analysis (breathing $60 \%$ oxygen) showed $\mathrm{pO}_{2} 11.1 \mathrm{kPa}, \mathrm{pCO}_{2}$ $3.8 \mathrm{kPa}$, lactate $10.6 \mathrm{mmol} / \mathrm{L}$.

High-dose oral prednisolone was started to reduce the suspected microvascular inflammatory process and she was transferred to the intensive care unit for intubation and mechanical ventilation. This proved extremely difficult, with high airways resistance. Despite ventilation and inotropic support, she died hours later, 16 days following admission.

At post-mortem, there was no evidence of large pulmonary thromboembolism to naked eye examination, but multiple carcinomatous emboli were apparent in the distal pulmonary arteries and veins on microscopy (Fig 2). The cause of death was determined to be pulmonary tumour emboli or thrombotic microangiopathy secondary to recurrence of breast cancer.

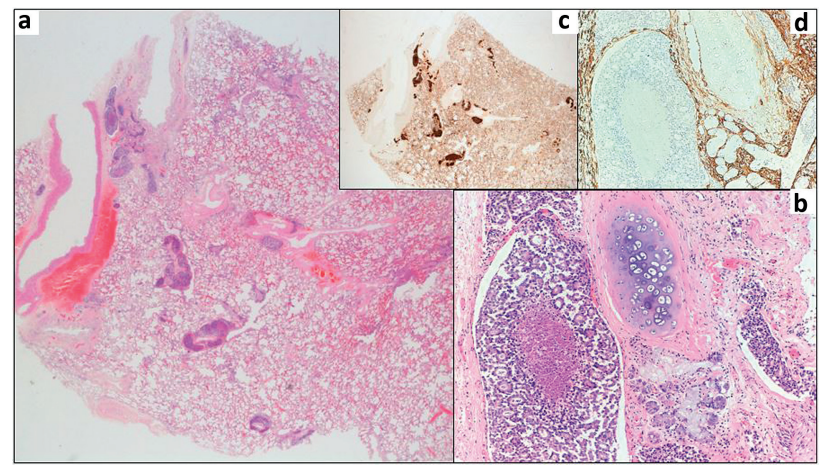

Fig 2. Post-mortem microscopy. a) Haematoxylin and eosin (H\&E)-stained low-power view showing extensive intravascular tumour. b) H\&E $10 \times$ magnification showing intravascular necrotic adenocarcinoma. c) Tumour cells stain positive (dark brown) for cytokeratin-7 (CK-7). d) CD34 highlights vascular endothelium (brown) and contrasts with the non-staining intravascular tumour. 


\section{Thrombotic microangiopathy}

Thrombotic microangiopathy results from the presence of metastatic tumour cells in the pulmonary vasculature. These emboli do not occlude the vessels, but induce local activation of the coagulation cascade leading to fibrocellular intimal proliferation, vasoconstriction and, in some patients, pulmonary hypertension., ${ }^{5,6}$

Characteristically, patients notice progressive dyspnoea. Hypoxaemia, a high A-a gradient and elevated D-dimer are seen. ${ }^{7,8}$ The chest $\mathrm{X}$-ray is often normal and no emboli are demonstrated on CTPA. ${ }^{7}$ Lymphangitis or vascular beading may occasionally be seen. Isotope perfusion scanning confirms multiple subsegmental peripheral defects. A definitive diagnosis is secured histocytologically from lung biopsy (transbronchial or open) or microvascular pulmonary sampling. ${ }^{9}$

At post-mortem, around a quarter of patients have an associated extrathoracic cancer; ${ }^{9}$ most commonly liver, breast, renal cell, gastric, prostate or choriocarcinoma. ${ }^{6}$ Overall, thrombotic microangiopathy portends a poor prognosis. However, if the patient's condition allows, surgical resection of the primary tumour (particularly renal cell carcinoma) or chemotherapy (breast cancers have shown the best response) can be considered. ${ }^{7,9}$

\section{References}

1 Pan AM, Stiell IG, Clement CM, Acheson J, Aaron SD. Feasibility of a structured 3-minute walk test as a clinical decision tool for patients presenting to the emergency department with acute dyspnoea. Emerg Med J 2009;26:278-82.
2 West JB, Luks AM. West's respiratory physiology: the essentials, 10th edn. Philadelphia: Lippincott Williams \& Wilkins, 2016.

3 Tunariu N, Gibbs SJR, Win Z et al. Ventilation-perfusion scintigraphy is more sensitive than multidetector CTPA in detecting chronic thromboembolic pulmonary disease as a treatable cause of pulmonary hypertension. J Nucl Med 2007;48:680-4.

4 Galiè N, Humbert M, Vachiery J-L et al. 2015 ESC/ERS guidelines for the diagnosis and treatment of pulmonary hypertension. Eur Heart ] 2016;37:67-119.

5 von Herbay A, Illes A, Waldherr R, Otto HF. Pulmonary tumor thrombotic microangiopathy with pulmonary hypertension. Cancer 1990;66:587-92.

6 Kane RD, Hawkins HK, Miller JA, Noce PS. Microscopic pulmonary tumor emboli associated with dyspnea. Cancer 1975;36:1473-82.

7 Chan CK, Hutcheon MA, Hyland RH et al. Pulmonary tumour embolism: a critical review of clinical, imaging, and hemodynamic features. J Thorac Imaging 1987;2:4-14.

8 Kridel R, Myit S, Pache J-C, Gaspoz J-M. Pulmonary tumor embolism: a rare cause of acute right heart failure with elevated D-dimers. J Thorac Oncol 2008;3:1482-3.

9 Schriner RW, Ryu JH, Edwards WD. Microscopic pulmonary tumor embolism causing subacute cor pulmonale: a difficult antemortem diagnosis. Mayo Clin Proc 1991;66;143-8.

Address for correspondence: Dr Edward Caple, University Hospital Llandough, Penlan Rd, Llandough, Penarth, Cardiff CF64 2XX, UK.

Email: capleejd@gmail.com

\section{Your decisions change lives for good.}

That's why, should something go wrong, we're with you every step of the way.

2018 , over $95 \%$ of members calling our 24-hour advice line were speaking to a medico-legal adviser within 20 seconds.

Visit themdu.com/consultants 